\title{
Peripheral Arterial Disease as an Independent Predictor for Excess Stroke Morbidity and Mortality in Primary-Care Patients: 5-Year Results of the getABI Study
}

\author{
Saskia H. Meves ${ }^{\mathrm{a}}$ Curt Diehm ${ }^{\mathrm{c}}$ Klaus Berger ${ }^{\mathrm{d}}$ David Pittrow $^{\mathrm{e}}$ Hans-Joachim Trampisch $^{\mathrm{b}}$ \\ Ina Burghaus $^{b}$ Gerhart Tepohl ${ }^{f}$ Jens-Rainer Allenberg ${ }^{h}$ Heinz G. Endres ${ }^{b}$ \\ Markus Schwertfeger ${ }^{i}$ Harald Darius $^{j}$ Roman L. Haberl ${ }^{g}$ for the getABI Study Group \\ a Department for Neurology, St. Josef Hospital and ${ }^{b}$ Department of Medical Informatics, Biometry and \\ Epidemiology, Ruhr University of Bochum, Bochum, 'Department of Internal Medicine/Vascular Medicine, \\ $\mathrm{SRH}-\mathrm{Clinic}$, Karlsbad-Langensteinbach, ${ }^{\mathrm{d} I n s t i t u t e}$ of Epidemiology and Social Medicine of the University Hospital \\ Münster, Münster, ${ }^{\mathrm{e}}$ Institute for Clinical Pharmacology, Technical University Dresden, Dresden, ${ }^{\mathrm{f}}$ Internist/Vascular \\ Medicine, Gefässzentrum Münchner Freiheit and ${ }^{9} \mathrm{Clinic}$ for Neurology, Klinikum Harlaching, Städtisches Klinikum \\ München $\mathrm{GmbH}$, Munich, h'Department of Vascular Surgery, University of Heidelberg, Heidelberg, 'Medical \\ Department, Sanofi-Aventis Pharma GmbH, and ${ }^{\mathrm{M}}$ Medical Clinic I, Vivantes Neukoelln Medical Center, Berlin, \\ Germany
}

\section{Key Words}

Peripheral arterial disease $\cdot$ Stroke mortality $\cdot$ Stroke morbidity $\cdot$ Ankle-brachial index $\cdot$ Primary care

\begin{abstract}
Background: There is controversial evidence with regard to the significance of peripheral arterial disease (PAD) as an indicator for future stroke risk. We aimed to quantify the risk increase for mortality and morbidity associated with PAD. Methods: In an open, prospective, noninterventional cohort study in the primary care setting, a total of 6,880 unselected patients $\geq 65$ years were categorized according to the presence or absence of PAD and followed up for vascular events or deaths over 5 years. PAD was defined as ankle-brachial index $(\mathrm{ABI})<0.9$ or history of previous peripheral revascularization and/or limb amputation and/or intermittent claudication. Associations between known cardiovascular risk factors including PAD and cerebrovascular mortality/events were analyzed in a multivariate Cox regression model. $\mathbf{R e}$ -
\end{abstract}

sults: During the 5-year follow-up [29,915 patient-years (PY)], 183 patients had a stroke (incidence per 1,000 PY: 6.1 cases). In patients with PAD $(n=1,429)$ compared to those without PAD $(n=5,392)$, the incidence of all stroke types standardized per 1,000 PY, with the exception of hemorrhagic stroke, was about doubled (for fatal stroke tripled). The corresponding adjusted hazard ratios were 1.6 (95\% confidence interval, $\mathrm{Cl}, 1.1-2.2)$ for total stroke, $1.7(95 \% \mathrm{Cl} 1.2-2.5)$ for ischemic stroke, 0.7 (95\% Cl 0.2-2.2) for hemorrhagic stroke, 2.5 (95\% Cl 1.2-5.2) for fatal stroke and $1.4(95 \% \mathrm{Cl} 0.9-2.1)$ for nonfatal stroke. Lower ABI categories were associated with higher stroke rates. Besides high age, previous stroke and diabetes mellitus, PAD was a significant independent predictor for ischemic stroke. Conclusions: The risk of stroke is substantially increased in PAD patients, and PAD is a strong independent predictor for stroke.

Copyright $\odot 2010$ S. Karger AG, Basel

These results were presented by R.L.H. at the International Stroke Conference in San Diego, Calif., USA, February 18-20, 2009.

\section{KARGER}

Fax +41613061234 E-Mail karger@karger.ch www.karger.com
(C) 2010 S. Karger AG, Base

$1015-9770 / 10 / 0296-0546 \$ 26.00 / 0$

Accessible online at:

www.karger.com/ced
Prof. Dr. Roman L. Haberl, Klinik für Neurologie und Neurologische Intensivmedizin, Neurologische Frührehabilitation, Neurophysiologie und Stroke Unit, Klinikum Harlaching, Städtisches Klinikum München GmbH Sanatoriumsplatz 2, DE-81545 München (Germany), Tel. +49 8962102257

Fax +49896210 2453, E-Mail roman.haberl@klinikum-muenchen.de 


\section{Background}

It is well known that individuals with peripheral arterial disease $(\mathrm{PAD})$ of the lower extremities are among the highest-risk vascular patients $[1,2]$. The presence of PAD is widely accepted as an indicator for generalized atherosclerosis, and the association between PAD and cardiovascular mortality and morbidity can be regarded as confirmed [3-8].

Patients with stroke or transient ischemic attack often have PAD $[9,10]$. However, it is still unclear whether PAD is also a good predictor for future cerebrovascular disease (CVD). A number of previous studies have reported conflicting results [11-14], and epidemiological data in the primary-care setting are limited. Such studies are needed, as the general physician holds a gatekeeper role in the diagnosis and management of PAD patients.

Thus, the aim of the present study was to quantify the CVD (stroke) risk of PAD patients compared to those without PAD in a typical primary-care sample of unselected elderly patients. For the identification of PAD, the ankle-brachial index (ABI) was used which is the ratio of anterior/posterior ankle systolic blood pressure to brachial systolic blood pressure. The ABI is in essence a screening-level assessment for PAD in the legs $[15,16]$.

When 0.9 or lower, it is very sensitive and specific for obstruction compared with the gold standard angiography [17] or compared with a full vascular laboratory evaluation [18].

\section{Methods}

\section{Patients and Study Evaluations}

The methods and design of the German Epidemiological Trial on Ankle-Brachial Index (getABI) have been described elsewhere in greater detail $[19,20]$. Briefly, the study is an open, noninterventional prospective cohort study that is monitored. A total of 344 general physicians (GPs) across Germany, who were trained and supervised by 34 vascular physicians in their vicinity, performed the study. A prevalence assessment of primary-care attendees, irrespective of their reason for seeing the doctor, was conducted within a prespecified week in October 2001. In each practice, the gender and age category of all patients attending the practice and seeing the doctor were recorded in a log file for each day of the week. The only exclusion criterion was life expectancy $\leq 6$ months. A total of 20 (in exceptional cases up to 25) eligible patients fulfilling the inclusion criteria (age $\geq 65$ years, patient being legally competent and able to cooperate appropriately and providing written informed consent) were recruited, preferably as evenly as possible over this week in order to avoid selection bias. The sex and age distribution of this elderly cohort $(n=6,880)$ was very similar to one of the general population ( $\geq 65$ years) in Germany, with a slight underrepresentation of the very old [19]. The protocol was approved by the ethics committee of the RuprechtKarls University Heidelberg, and all patients provided informed consent.

As the study is purely observational, no recommendation was given to physicians on how to manage their patients, irrespective of PAD status.

\section{Examinations at Baseline}

A short physical examination was performed at baseline. Medical history assessment included the following conditions: (a) history of revascularization (coronary/at carotids) or myocardial infarction [myocardial infarction, coronary revascularization procedures, revascularization procedures on the carotid arteries (and no stroke)], (b) history of stroke, (c) history of peripheral revascularization or amputation (due to PAD), i.e. a history of revascularization procedures on the peripheral arteries, or amputation (minor and major form) of the lower extremities on account of PAD, (d) intermittent claudication (i.e. pain in the calf muscles while walking or during other exertion and disappearing within $10 \mathrm{~min}$ at rest), (e) risk factors, e.g. systolic blood pressure, diabetes, lipid disorders or smoking. Subjects were defined as having diabetes mellitus (i) if they had been assigned the clinical diagnosis by their physician and/or (ii) if their $\mathrm{HbA}_{1 \mathrm{c}}$ was $\geq 6.5 \%$ (criterion used in 94 cases) and/or (iii) if they were receiving any oral antidiabetic drug and/or insulin at baseline. The $\geq 6.5 \% \mathrm{HbA}_{1 \mathrm{c}}$ value is above the typically used upper reference value of $6.0 \%$ and is highly specific for diabetes $[21,22]$. Subjects were defined as taking hypertension medication, if they were receiving $\mathrm{AT}_{1}$ receptor antagonists and/or ACE inhibitors and/or diuretics at baseline. As $\beta$-blockers and calcium channel blockers are often used in indications other than hypertension (e.g. coronary heart disease, heart failure), we excluded them from the definition of hypertension. Subjects were defined as having lipid disorders (i) if they had been assigned the clinical diagnosis by their physician and/or (ii) if they were receiving statins and/or fibrates and/or (iii) if their total cholesterol was $\geq 200 \mathrm{mg} / \mathrm{dl}$ at baseline and/or (iv) if their triglyceride value was $\geq 150 \mathrm{mg} / \mathrm{dl}$ at baseline. All laboratory examinations were performed centrally. A cigarette smoking history was taken from all study subjects (never, current, past). Information on atrial fibrillation was retrieved for stroke patients from patient charts and physician letters.

\section{PAD Definition}

GPs were specifically trained by vascular physicians to perform $\mathrm{ABI}$ measurements under standardized conditions on the resting patient. Doppler measurements were done with the Kranzbühler 8-MHz device, General Electrics, Solingen, Germany. Blood pressure measurements and ABI calculations were performed according to the recommendations of the American Heart Association [23, 24]. The ABI was calculated separately for each leg by dividing the higher of the 2 systolic pressures (tibial posterior and anterior artery) above the ankle, by the average of the right and left brachial artery pressures. If there was a discrepancy $\geq 10 \mathrm{~mm} \mathrm{Hg}$ in blood pressure values between the two arms, the higher reading was used for the ABI. The lower of the two ABI values was used for analyses.

PAD was defined as either symptomatic or asymptomatic PAD. Asymptomatic PAD was defined as resting ABI $<0.90[1,2$, 24], with absence of prior peripheral arterial events or clinical symptoms indicative of intermittent claudication. Symptomatic 
PAD was defined as intermittent claudication and/or history of peripheral vascular revascularization and/or limb amputation due to PAD. Fifty-nine patients with incompressible arteries (Mönckeberg sclerosis) as indicated by an $\mathrm{ABI}>1.5$ were excluded (52.5\% of these were diabetic), as in other studies, to avoid misclassification $[25,26]$, for a total of 6,821 patients in the analyses. Cases with missing ABI values $(n=8)$ and no past peripheral events or intermittent claudication were classified as patients without PAD.

\section{Definition of Stroke Events during Follow-Up}

Information on patients' deaths and vascular events was obtained from the participating GPs in regular prespecified intervals (at 6 months, and at 1, 3 and 5 years) on case record forms detailing the event. At the 5-year-follow-up visit, GPs were requested to fill in the case record form, which specifically asked for occurrence of strokes, or hospitalizations because of a cerebrovascular event, and death because of a cerebrovascular event (other vascular events were also assessed). Afterwards GPs were asked to supply all available information about these events (e.g. hospital discharge letter) to the study center where two experienced neurologists tried to verify whether there was indeed a stroke. If necessary, the GPs and the hospitals were contacted and a final decision was made. Events qualified as stroke if common focal symptoms lasted longer than $24 \mathrm{~h}$ or a definite new focal lesion in brain imaging was visualized. Partly due to imprecise or unspecific symptom description of transient ischemic attacks, these were excluded from further analysis. The following cerebrovascular events were categorized: total strokes; ischemic and hemorrhagic strokes; fatal and nonfatal strokes. All strokes were further verified and adjudicated by two neurologists independently (S.M. and K.B.), who were unaware of PAD status of patients. In case of deviating opinions [27], consensus was reached by discussion. Particular attention was paid to the categorization of stroke events into hemorrhagic and ischemic [28].

\section{Statistical Analyses}

Univariate and multivariate Cox regression analyses were performed, and the corresponding hazard ratios ( $\mathrm{HR}$, and their $95 \%$ confidence intervals, CI) were calculated to assess associations between PAD (and other risk factors) and 5-year CVD mortality/ morbidity. In addition to PAD (yes/no), or PAD (symptomatic/ asymptomatic) or ABI categories, respectively, the following variables were included in all multivariate statistical models (each yes or no, if not indicated otherwise): age (above/below median), gender (male/female), smoking status (never/ever), BMI (above/below 30), history of revascularization (coronary/at carotids) or myocardial infarction, history of stroke, presence of diabetes, systolic blood pressure per $10 \mathrm{~mm} \mathrm{Hg}$ (continuous), hypertension medication, lipid disorders and homocysteine (below/above 4th quintile, $19.1 \mu \mathrm{mol} / \mathrm{l})$. For calculating the incidence rates, only the first event was taken into account. To illustrate possible linear relations between low ABI values and the risk of CVD deaths or events, the ABI was categorized according to the cutoff points 1.1, $0.9,0.7$ and 0.5 . Patients with a history of peripheral revascularization or amputation due to PAD at baseline were included as a separate category. Time-to-event distributions in the individual categories were summarized with Kaplan-Meier curves.

Statistical significance was accepted at the two-sided $0.05 \mathrm{lev}$ $\mathrm{el}$, and all confidence intervals were computed at the $95 \%$ level.
Statistical analyses were performed with SAS version 9.1 (SAS Institute Inc., Cary, N.C., USA).

\section{Patient Disposition at Follow-Up}

At 5 years, the survival status (dead/alive) of all but 4 of the 6,880 patients was known (>99.9\%). In 5,032 of 6,049 patients still alive, a clinical examination at study end could be performed, whereas in 273 cases information could be obtained only indirectly, e.g. via telephone. From the 309 patients with potential strokes reported by the GPs (233 nonfatal strokes, 76 deaths because of a cerebrovascular event), 185 were confirmed as stroke (150 nonfatal strokes, 35 deaths because of a cerebrovascular event). Two strokes ( 1 ischemic) occurred in the 59 patients with $\mathrm{ABI}>1.5$; one of the patients was diabetic.

Patients lost to follow-up were included in the corresponding time-to-event analyses with censoring at the date of last information.

\section{Results}

\section{Baseline Characteristics}

A total of 6,821 patients aged 65 years or older were included in the analyses. Table 1 shows the baseline characteristics of the 5,392 individuals without PAD and the 1,429 persons categorized as PAD patients $(21.0 \%)$, of whom 836 had asymptomatic PAD (12.3\%) and 593 symptomatic PAD (8.7\%). A total of 311 patients, i.e. 113 (7.9\%) in the PAD group and 198 (3.7\%) in patients without PAD, had a history of stroke. PAD patients were somewhat older than patients without PAD, were more commonly current or past smokers, and had a higher burden of concomitant diseases, in particular diabetes mellitus.

\section{Stroke Mortality and Morbidity by PAD Status}

During the 5-year follow-up (29,915 patient-years, PY), 183 patients had a stroke (incl. fatal; 6.1 cases per 1,000 PY; 95\% CI 5.2-7.1). For comparison, the incidence per 1,000 PY for a myocardial infarction, a coronary revascularization and/or death because of a cardiovascular event was 17.7 (95\% CI 16.1-19.3). On the left, figure 1 shows the PY and numbers of stroke events, by type (ischemic vs. hemorrhagic), and outcomes (nonfatal vs. fatal).

Fatal strokes (35 cases) were much less frequent than nonfatal strokes (149 cases). In patients with PAD, the raw incidence of all stroke types per 1,000 PY, with the exception of hemorrhagic stroke, was about doubled (for fatal stroke tripled). The corresponding unadjusted HR were 2.1 (95\% CI 1.5-2.9) for total stroke, 2.4 (95\% CI 1.7-3.4) for ischemic stroke, 0.9 (95\% CI 0.2-2.6) for hemorrhagic stroke, 3.4 (95\% CI 1.7-6.6) for fatal stroke and 1.9 (95\% CI 1.3-2.8) for nonfatal stroke. 
Table 1. Patient characteristics at inclusion, in the total cohort and by PAD status

\begin{tabular}{|c|c|c|c|c|c|c|}
\hline & \multicolumn{2}{|c|}{ All patients } & \multicolumn{2}{|c|}{ No/unknown PAD } & \multicolumn{2}{|l|}{ PAD } \\
\hline & $\mathrm{n}$ & $\begin{array}{l}\% \text { or } \\
\text { mean } \pm \mathrm{SD}\end{array}$ & $\mathrm{n}$ & $\begin{array}{l}\% \text { or } \\
\text { mean } \pm \mathrm{SD}\end{array}$ & $\mathrm{n}$ & $\begin{array}{l}\% \text { or } \\
\text { mean } \pm S D\end{array}$ \\
\hline All & 6,821 & & 5,392 & & 1,429 & \\
\hline Age & 6,821 & $72.5 \pm 5.3$ & 5,392 & $72.2 \pm 5.1$ & 1,429 & $73.9 \pm 5.6$ \\
\hline \multicolumn{7}{|l|}{ Gender } \\
\hline Female & 3,959 & 58.0 & 3,187 & 59.1 & 772 & 54.0 \\
\hline Male & 2,862 & 42.0 & 2,205 & 40.9 & 657 & 46.0 \\
\hline \multicolumn{7}{|l|}{ Smoking status } \\
\hline Never & 3,687 & 54.1 & 3,083 & 57.2 & 604 & 42.3 \\
\hline Past & 2,500 & 36.7 & 1,888 & 35.0 & 612 & 42.8 \\
\hline Current & 634 & 9.3 & 421 & 7.8 & 213 & 14.9 \\
\hline BMI & 6,816 & $27.3 \pm 4.1$ & 5,387 & $27.3 \pm 4.1$ & 1,429 & $27.4 \pm 4.2$ \\
\hline \multicolumn{7}{|l|}{ Diabetes mellitus } \\
\hline No/unknown & 5,090 & 74.6 & 4,172 & 77.4 & 918 & 64.2 \\
\hline Yes & 1,731 & 25.4 & 1,220 & 22.6 & 511 & 35.8 \\
\hline \multicolumn{7}{|l|}{ Hypertension medication } \\
\hline No/unknown & 3,311 & 48.5 & 2,811 & 52.1 & 500 & 35.0 \\
\hline Yes & 3,510 & 51.5 & 2,581 & 47.9 & 929 & 65.0 \\
\hline \multicolumn{7}{|l|}{ Lipid disorders } \\
\hline No/unknown & 1,158 & 17.0 & 953 & 17.7 & 205 & 14.3 \\
\hline Yes & 5,663 & 83.0 & 4,439 & 82.3 & 1,224 & 85.7 \\
\hline \multicolumn{7}{|l|}{ History of stroke } \\
\hline No/unknown & 6,510 & 95.4 & 5,194 & 96.3 & 1,316 & 92.1 \\
\hline Yes & 311 & 4.6 & 198 & 3.7 & 113 & 7.9 \\
\hline \multicolumn{7}{|c|}{ History of revascularization (coronary/at carotids) or myocardial infarction } \\
\hline No/unknown & 5,975 & 87.6 & 4,854 & 90.0 & 1,121 & 78.4 \\
\hline Yes & 846 & 12.4 & 538 & 10.0 & 308 & 21.6 \\
\hline Systolic blood pressure & 6,821 & $146 \pm 22$ & 5,392 & $144 \pm 21$ & 1,429 & $151 \pm 24$ \\
\hline
\end{tabular}

A total of 59 patients with $\mathrm{ABI}>1.5$ were excluded from the analyses. For definition of PAD, diabetes mellitus, lipid disorders etc., see Methods section.

The increased risk of PAD patients for stroke remained significant for total stroke, ischemic stroke and fatal stroke (but not for hemorrhagic stroke or nonfatal stroke) after adjustment for age, history of stroke events, antihypertensive medication, gender and known stroke risk factors as shown in figure 1, on the right. Risk increases after adjustment were between 1.4 (nonfatal stroke) and 2.5 (fatal stroke). Excluding patients with previous strokes from analysis, there is no substantial change in the prognostic effect of PAD for ischemic stroke [1.8 (1.2-2.7) vs. $1.7(1.2-2.5)]$.

Figure 2 illustrates the comparison of asymptomatic and symptomatic PAD patients for ischemic stroke. Compared to patients without PAD, the risk increase was somewhat higher in asymptomatic PAD patients than in symptomatic PAD patients. Differences for all stroke types did not reach significance (data not shown).
Stroke Morbidity and Mortality by ABI Category

In the analysis of ischemic strokes by ABI category, patients with ABI 1.1-1.5 (3.8 events) and 0.9-1.1 (4.4 events) had the lowest event rate per 1,000 PY, while with decreasing ABI event rates increased substantially (fig. 2). This finding is illustrated with event-free survival over time by ABI category, in figure 3. Similar outcomes were found for total stroke, and for nonfatal and fatal stroke.

\section{Association of Risk Factors and Incident Ischemic Stroke}

In the multivariate analysis of cardiovascular risk factors (fig. 4), statistically significant predictors for ischemic stroke were higher age (defined as above the median of 72 years: HR 2.0), history of stroke (HR 1.9), PAD (HR 1.9), diabetes mellitus (HR 1.5) and systolic blood pressure (per $10 \mathrm{~mm} \mathrm{Hg:} \mathrm{HR} \mathrm{1.1).} \mathrm{Conversely,} \mathrm{history} \mathrm{of} \mathrm{re-}$ 


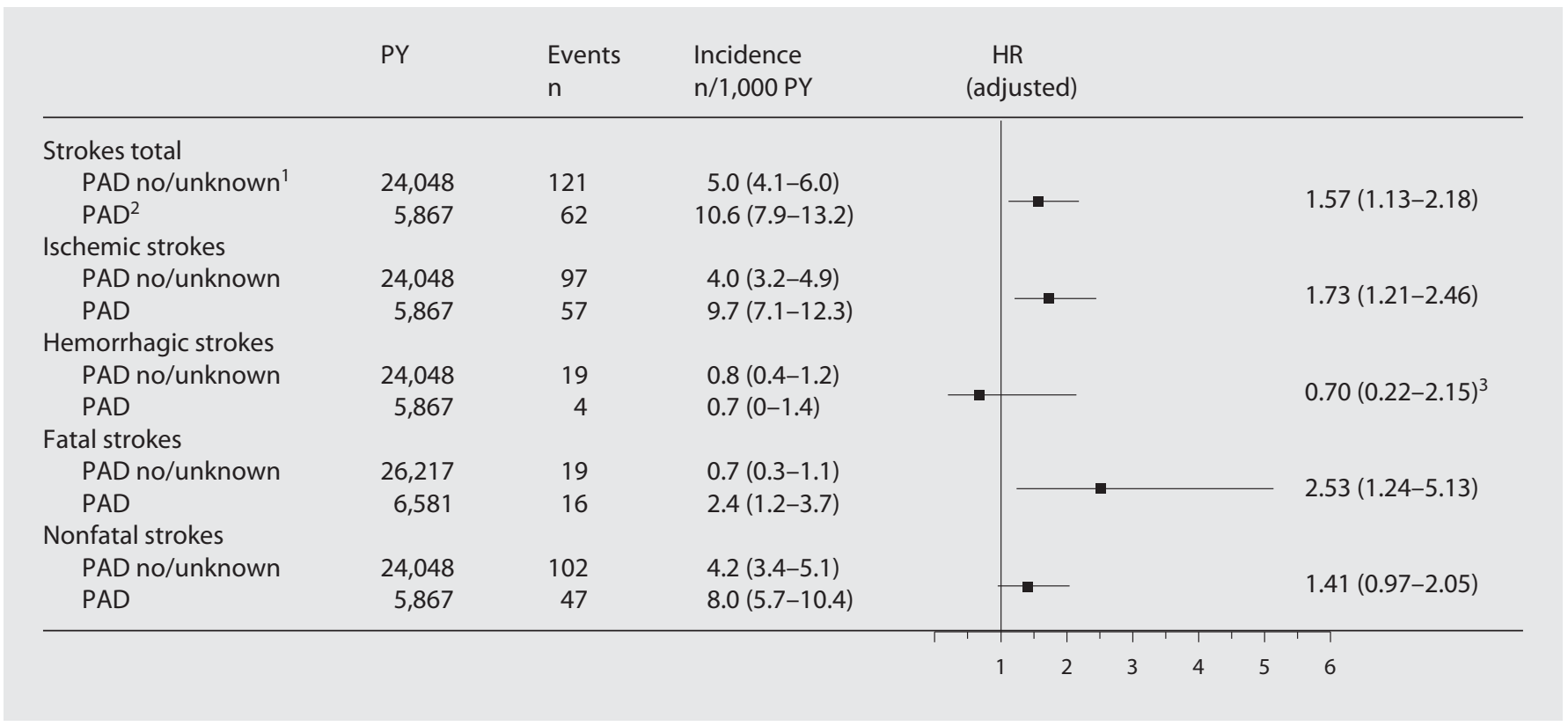

Fig. 1. Stroke events during 5-year follow-up according to various definitions and respective adjusted $\mathrm{HR}$ in patients with and without PAD. Figures in parentheses are $95 \%$ CI. A total of 59 patients with $\mathrm{ABI}>1.5$ were excluded from the analyses. One patient had a fatal and a nonfatal stroke and was counted in both subgroups. For the analysis, only the first event was taken into account. HR as a result of a Cox regression analysis: adjusted for diabetes mellitus, hypertension medication, systolic blood pressure per $10 \mathrm{~mm}$
$\mathrm{Hg}$, lipid disorders, age (>median), sex, BMI ( $\geq 30$ ), smoking (ever), history of revascularization (coronary/at carotids) or myocardial infarction, history of stroke and homocysteine ( $>4$ th quintile, 19.1 $\mu \mathrm{mol} / \mathrm{l})$ at baseline. For definitions, see Methods section. ${ }^{1}$ Reference, $n=5,392 .{ }^{2} n=1,429 .{ }^{3}$ Not adjusted for history of revascularization (coronary/at carotids) or myocardial infarction because of lack of events. vascularization (at carotids/coronary) or myocardial infarction was not found to be associated with incident ischemic strokes, nor was lipid disorders.

The prevalence of atrial fibrillation, as documented in patient charts and physician letters, did not significantly differ in stroke patients without PAD (35 patients, 28.9\%) versus stroke patients with PAD (15 patients, $24.2 \%, \mathrm{p}=$ 0.5 in $\chi^{2}$ test).

\section{Discussion}

We have recently reported a substantially increased risk of all-cause and cardiovascular mortality after 3-year and 5-year follow-ups associated with a low ABI in this cohort $[7,20]$. The present analysis indicates that such PAD patients also carry a substantially elevated risk for ischemic stroke, which is about doubled compared to individuals without PAD.

Previously, a series of major community studies of at least 3 years' duration investigated the relative risk in- crease in incident stroke events in patients with a low $A B I$ $<0.9$ compared to patients without PAD. In the Cardiovascular Health Study (5,888 Medicare patients $\geq 65$ years), the unadjusted relative risk (RR) associated with a low ABI was 1.9 (95\% CI 1.4-2.7), and the adjusted RR was 1.1 (95\% CI 0.7-1.7) [20, 29]. In the Honolulu Heart Program (2,767 men aged 71-93 years of Japanese ancestry), the unadjusted RR was 2.1 (95\% CI 1.3-3.5), and the adjusted RR was 2.0 (95\% CI 1.1-3.5) [30]. In the ARIC study (14,839 men and women aged 45-64 years in 4 US communities), the unadjusted RR was 3.3 (95\% CI 2.15.3), and the adjusted RR was 1.9 (95\% CI 0.8-4.8) [31]. Two other studies that used a slightly different ABI cutoff for the PAD diagnosis $(\leq 0.9)$, namely the Edinburgh Artery Study (55- to 74-year-old primary-care patients) with an adjusted RR of 2.0 (95\% CI 1.1-3.8) [11], and a small Swedish study of 68-year-old men in a community sample (adjusted RR 2.0; 95\% CI 1.1-3.7) [12] came to similar conclusions. Taken together, all these studies found before adjustment a doubled or tripled stroke risk in patients with low $\mathrm{ABI}$, and the risk increase in the majority 


\begin{tabular}{|c|c|c|c|c|c|c|}
\hline & $\begin{array}{l}\text { Patients } \\
\mathrm{n}\end{array}$ & PY & $\begin{array}{l}\text { Events } \\
\mathrm{n}\end{array}$ & $\begin{array}{l}\text { Incidence of } \\
\text { ischemic strokes } \\
\mathrm{n} / 1,000 \mathrm{PY}\end{array}$ & \multicolumn{2}{|l|}{$\begin{array}{l}\text { HR } \\
\text { (adjusted) }\end{array}$} \\
\hline All & 6,821 & 29,915 & 154 & $5.1(4.3-6.0)$ & & \\
\hline PAD no/unknown & 5,392 & 24,048 & 97 & $4.0(3.2-4.9)$ & & reference \\
\hline PAD total & 1,429 & 5,867 & 57 & $9.7(7.1-12.3)$ & - & $1.73(1.21-2.46)$ \\
\hline PAD asymptomatic & 836 & 3,471 & 36 & $10.4(6.9-13.8)$ & $\rightarrow-$ & $1.91(1.28-2.86)$ \\
\hline \multirow[t]{2}{*}{ PAD symptomatic } & 893 & 2,397 & 21 & $8.8(5.0-12.6)$ & - & $1.51(0.91-2.51)$ \\
\hline & & \multicolumn{3}{|c|}{ PAD symptomatic vs. PAD asymptomatic } & - & $0.82(0.47-1.43)$ \\
\hline \multicolumn{7}{|l|}{$\mathrm{ABI}$ category } \\
\hline Missing & 8 & 31 & 0 & 0 (n.a.) & & \\
\hline $1.5 \geq A B I \geq 1.1$ & 2,172 & 9,716 & 37 & $3.8(2.5-5.1)$ & & reference \\
\hline $1.1>A B I \geq 0.9$ & 3,414 & 15,140 & 67 & $4.4(3.3-5.5)$ & - & $1.13(0.73-1.72)$ \\
\hline $0.9>A B I \geq 0.7$ & 800 & 3,359 & 30 & $8.9(5.7-12.2)$ & 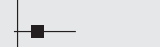 & $1.54(0.90-2.62)$ \\
\hline $0.7>A B I \geq 0.5$ & 214 & 837 & 12 & $14.3(6.2-22.5)$ & $\longrightarrow$ & $2.32(1.12-4.80)$ \\
\hline $\mathrm{ABI}<0.5$ & 51 & 182 & 3 & 16.5 (n.a.) & 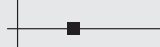 & $2.53(0.70-9.09)$ \\
\hline $\begin{array}{l}\text { History of peripheral } \\
\text { revascularization or } \\
\text { amputation (due to } \\
\text { PAD) at baseline }\end{array}$ & 162 & 649 & 5 & $7.7(0.9-14.5)$ & $\square$ & $1.42(0.51-3.91)$ \\
\hline
\end{tabular}

Fig. 2. Ischemic stroke according to presence/absence of PAD or according to ABI category. Figures in parentheses are 95\% CI; n.a. = not assessed. A total of 59 patients with $A B I>1.5$ were excluded from the analyses. HR as a result of a Cox regression analysis: adjusted for diabetes mellitus, hypertension medication, sys- tolic blood pressure per $10 \mathrm{~mm} \mathrm{Hg}$, lipid disorders, age (>median), sex, BMI ( $\geq 30$ ), smoking (ever), history of revascularization (coronary/at carotids) or myocardial infarction, history of stroke and homocysteine (>4th quintile, $19.1 \mu \mathrm{mol} / \mathrm{l})$ at baseline. For definitions, see Methods section.
Fig. 3. Risk of ischemic stroke by ABI category. Event-free survival refers to the nonoccurrence of ischemic strokes.

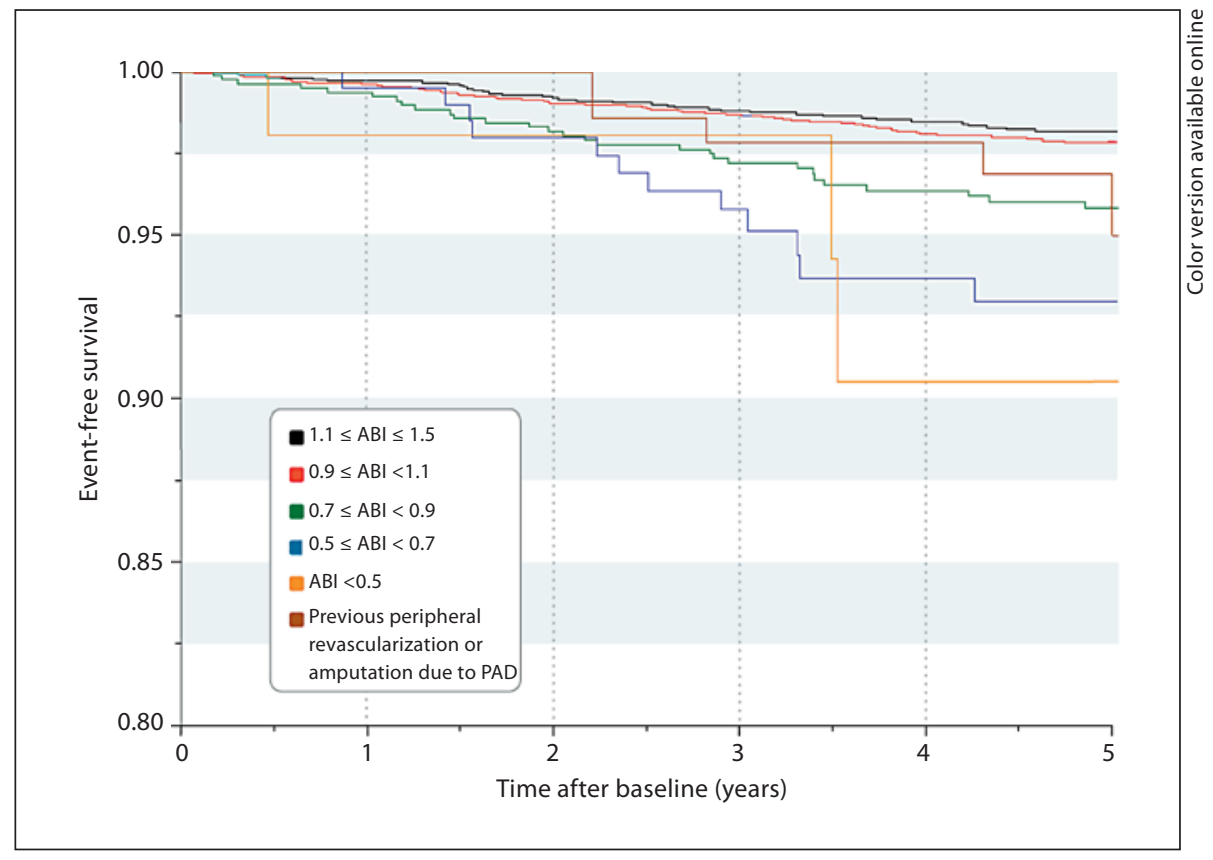

Cerebrovasc Dis 2010;29:546-554 


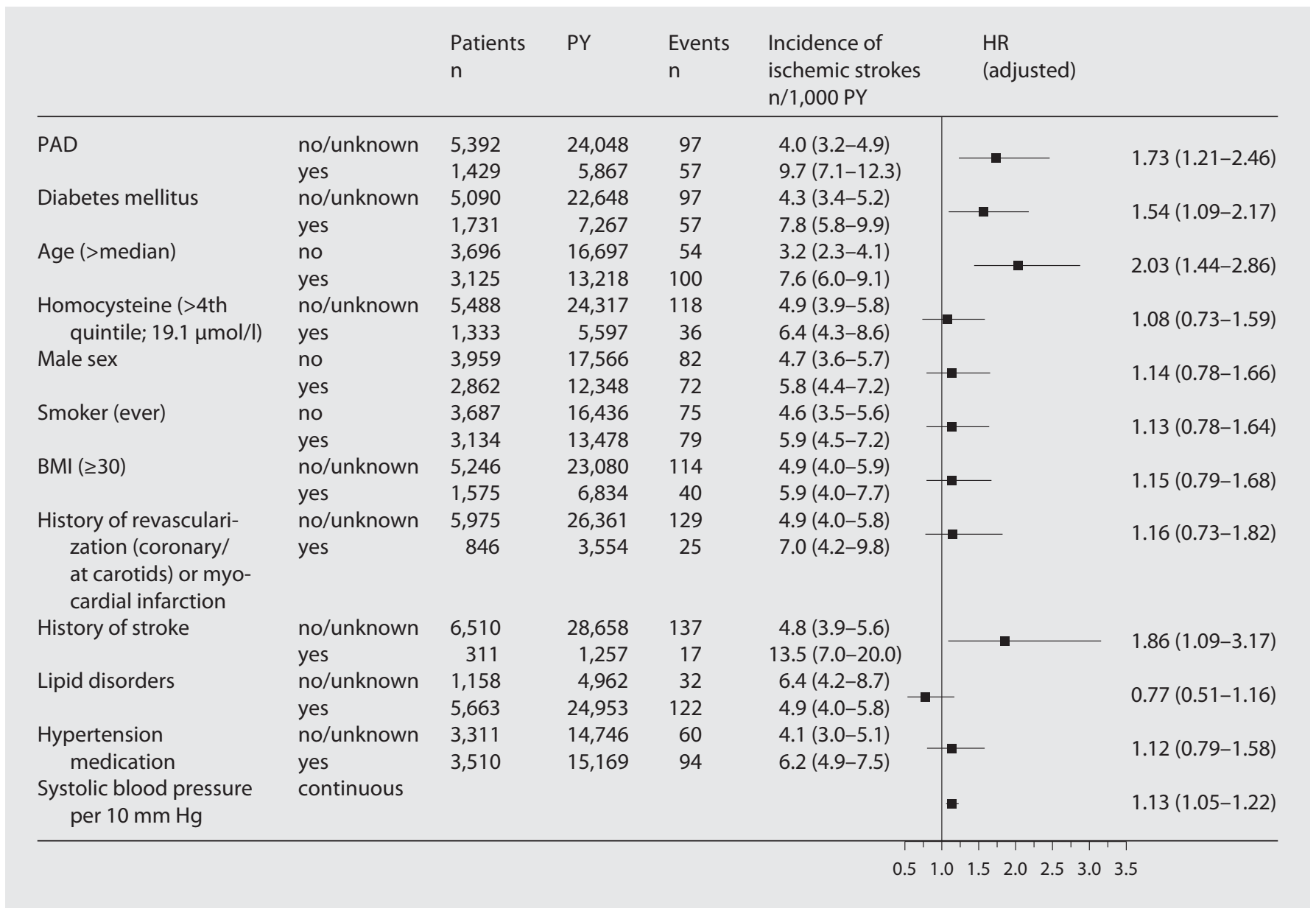

Fig. 4. Factors associated with incident ischemic stroke events. Figures in parentheses are $95 \%$ CI. A total of 59 patients with ABI $>1.5$ were excluded from the analyses. HR as a result of a Cox regression analysis: adjusted for diabetes, hypertension medication, systolic blood pressure per $10 \mathrm{~mm} \mathrm{Hg}$, lipid disorders, age (>me-

of these studies, but not all, remained significant after adjustment for other risk factors.

Our study is one of the largest with a relatively high number of stroke events. It should be noted that in terms of cardiovascular risk, population-based studies as well as our study were unequivocal, confirming that a low $\mathrm{ABI}$ is an independent predictor of future cardiovascular events $[8,20]$.

The present study documents a linear increase in risk (lowest in ABI 1.1-1.5) to the 0.7-0.5 category. In the category of patients with an $A B I>1.5(n=59)$, the number of strokes (2) was too low to assess whether there is a higher risk of these patients with calcified arteries, as has been suggested in two previous studies [32, 33], who found a $\mathrm{U}$-shaped risk curve related to the ABI. dian), sex, BMI ( $\geq 30$ ), smoking (ever), history of revascularization (coronary/at carotids) or myocardial infarction, history of stroke and homocysteine ( $>4$ th quintile, $19.1 \mu \mathrm{mol} / \mathrm{l})$ at baseline. For definitions, see Methods section.

In our analysis of associations between various known cardiovascular risk factors and ischemic stroke, there was no significant difference in terms of comorbid atrial fibrillation in PAD patients versus non-PAD patients who had suffered a stroke. However, the difference in the PAD emerged as one of the significant factors, similarly to previous analyses that documented the link between PAD and death due to coronary artery disease [7]. This result clearly contrasts with the Rotterdam study, in which a low ABI lost its predictive ability after adjustment for other cardiovascular risk factors [34]. Notably, while previous stroke events predicted incident (recurrent) strokes, we did not find a relation between prior revascularizations (at carotids or coronaries) as indicators of less severe vascular events. In contrast to validated scores and their al- 
gorithms for the prediction of recurrent strokes in the long term such as the Stroke Prognosis Instrument I-II [35] or the Essen Stroke Risk Score [36], previous myocardial infarction did not predict strokes. Lipid disorders in our study were mostly characterized by the intake of statins, which might explain the protective effect of the condition in the multivariate model.

Our study has strengths in terms of representativeness for the primary care setting, high data quality due to onsite monitoring of centers, very low attrition rates and nearly complete follow-ups concerning life status. However, some limitations have to be considered. While stroke diagnoses taken from hospital or GP records were verified centrally to the best extent possible, misclassifications of events cannot be entirely excluded [28]. However, such misclassifications would occur in both groups, and our results are consistent with the findings of previous smaller studies as described above. Second, data on medication use were only recorded at baseline, but not during the follow-up. It is conceivable that physicians increased the intensity of antihypertensive, lipid-lowering and/or antiplatelet treatment in the newly diagnosed PAD patients in the absence of blinding, leading to confounding due to medical care [37]. This could have led to an underestimation of the risk associated with PAD, but would not alter the conclusions drawn from the study. It is more likely that GPs did not intensify treatment in PAD patients, as undertreatment seems to be the rule rather than an exception in these patients $[1,2]$.

Summing up, primary-care patients with (asymptomatic or symptomatic) PAD have a substantially increased risk of stroke, which was significant for the all-cause, ischemic and fatal stroke categories. In the context of other studies, our findings confirm the value of PAD (and a low ABI) for the prediction of incident vascular events. Elderly patients in the primary-care setting should be screened for PAD to enable stringent treatment of modifiable cardiovascular risk factors to reduce the risk of ischemic stroke and other vascular events.

\section{Acknowledgments}

This study was supported by an unrestricted educational grant by Sanofi-Aventis, Berlin, Germany (2001-2007), and the German Federal Ministry of Education and Research (since 2007).

\section{Disclosure}

Dr. Schwertfeger is a full-time employee of Sanofi-Aventis Pharma, which is one of the sponsors of the study.

\section{References}

1 Hirsch AT, Haskal ZJ, Hertzer NR, et al: ACC/AHA 2005 practice guidelines for the management of patients with peripheral arterial disease (lower extremity, renal, mesenteric, and abdominal aortic): a collaborative report from the American Association for Vascular Surgery/Society for Vascular Surgery, Society for Cardiovascular Angiography and Interventions, Society for Vascular Medicine and Biology, Society of Interventional Radiology, and the ACC/AHA Task Force on Practice Guidelines (Writing Committee to Develop Guidelines for the Management of Patients with Peripheral Arterial Disease): endorsed by the American Association of Cardiovascular and Pulmonary Rehabilitation, National Heart, Lung and Blood Institute, Society for Vascular Nursing, Transatlantic Inter-Society Consensus and Vascular Disease Foundation. Circulation 2006;113:e463-e654.
2 Norgren L, Hiatt W, Dormandy J, Nehler M, Harris K, Fowkes F: Inter-society consensus for the management of peripheral arterial disease (TASC II). Eur J Vasc Endovasc Surg 2007;33(suppl 1):S1-S75.

3 Criqui MH, Langer RD, Fronek A, et al: Mortality over a period of 10 years in patients with peripheral arterial disease. N Engl J Med 1992;326:381-386.

4 Newman AB, Sutton-Tyrrell K, Vogt MT, Kuller LH: Morbidity and mortality in hypertensive adults with a low ankle/arm blood pressure index. JAMA 1993;270:487-489.

5 Lee AJ, Price JF, Russell MJ, Smith FB, van Wijk MCW, Fowkes FGR: Improved prediction of fatal myocardial infarction using the ankle brachial index in addition to conventional risk factors: the Edinburgh Artery Study. Circulation 2004;110:3075-3080.

6 Hooi JD, Kester AD, Stoffers HE, Rinkens PE, Knottnerus JA, van Ree JW: Asymptomatic peripheral arterial occlusive disease predicted cardiovascular morbidity and mortality in a 7-year follow-up study. J Clin Epidemiol 2004;57:294-300.
7 Diehm C, Lange S, Darius H, et al: Association of low ankle brachial index with high mortality in primary care. Eur Heart J 2006; 27:1743-1749.

8 Doobay AV, Anand SS: Sensitivity and specificity of the ankle-brachial index to predict future cardiovascular outcomes: a systematic review. Arterioscler Thromb Vasc Biol 2005;25:1463-1469.

9 Topakian R, Nanz S, Rohrbacher B, Koppensteiner R, Aichner FT: High prevalence of peripheral arterial disease in patients with acute ischaemic stroke. Cerebrovasc Dis 2009;29:248-254.

10 Rother J, Alberts MJ, Touze E, et al: Risk factor profile and management of cerebrovascular patients in the REACH Registry. Cerebrovasc Dis 2008;25:366-374.

11 Leng GC, Fowkes FG, Lee AJ, Dunbar J, Housley E, Ruckley CV: Use of ankle brachial pressure index to predict cardiovascular events and death: a cohort study. BMJ 1996; 313:1440-1444. 
12 Ogren M, Hedblad B, Isacsson S-O, Janzon L, Jungquist G, Lindell S-E: Ten year cerebrovascular morbidity and mortality in 68-yearold men with asymptomatic carotid stenosis. BMJ 1995;310:1294-1298.

13 Newman AB, Shemanski L, Manolio TA, et al: Ankle-arm index as a predictor of cardiovascular disease and mortality in the Cardiovascular Health Study. The Cardiovascular Health Study Group. Arterioscler Thromb Vasc Biol 1999;19:538-545.

14 Ovbiagele B: Association of ankle-brachial index level with stroke. J Neurol Sci 2009; 276:14-17.

15 Grundy SM, Balady GJ, Criqui MH, et al: Primary prevention of coronary heart disease: guidance from Framingham - a statement for healthcare professionals from the AHA Task Force on risk reduction. Circulation 1998;97:1876-1887.

16 Belch JJF, Topol EJ, Agnelli G, et al: Critical issues in peripheral arterial disease detection and management: a call to action. Arch Intern Med 2003;163:884-892.

17 Yao ST, Hobbs JT, Irvine WT: Ankle systolic pressure measurements in arterial disease affecting the lower extremities. Br J Surg 1969;56:676-679.

18 Stoffers H, Kester A, Kaiser V, Rinkens P, Kitslaar P, Knottnerus J: The diagnostic value of the measurement of the ankle-brachial systolic pressure index in primary health care. J Clin Epidemiol 1996;49:1401-1405.

19 Diehm C, Schuster A, Allenberg H, et al: High prevalence of peripheral arterial disease and comorbidity in 6,880 primary care patients: cross-sectional study. Atherosclerosis 2004;172:95-105.

20 Diehm C, Allenberg JR, Pittrow D, et al: Mortality and vascular morbidity in older adults with asymptomatic versus symptomatic peripheral artery disease. Circulation 2009:120:2053-2061.
21 Lange S, Diehm C, Darius H, et al: High prevalence of peripheral arterial disease and low treatment rates in elderly primary care patients with diabetes. Exp Clin Endocrinol Diabetes 2004;112:566-573.

22 Dormandy JA, Betteridge DJ, Schernthaner G, Pirags V, Norgren L: Impact of peripheral arterial disease in patients with diabetes - results from Proactive (Proactive 11). Atherosclerosis 2009;202:272-281.

23 Orchard TJ, Strandness DE Jr: Assessment of peripheral vascular disease in diabetes. Report and recommendations of an international workshop sponsored by the American Diabetes Association and the American Heart Association September 18-20, 1992 New Orleans, Louisiana. Circulation 1993; 88:819-828.

24 Greenland P, Abrams J, Aurigemma GP, et al: Prevention conference V. Beyond secondary prevention: identifying the high-risk patient for primary prevention. Noninvasive tests of atherosclerotic burden. Circulation 2000; 101:E16-E22.

25 Meijer WT, Hoes AW, Rutgers D, Bots ML, Hofman A, Grobbee DE: Peripheral arterial disease in the elderly: the Rotterdam Study. Arterioscler Thromb Vasc Biol 1998;18:185192.

26 McDermott MM, Greenland P, Liu K, et al: The ankle brachial index is associated with leg function and physical activity: the Walking and Leg Circulation Study. Ann Intern Med 2002;136:873-883

27 Atiya M, Kurth T, Berger K, Buring JE, Kase CS: Interobserver agreement in the classification of stroke in the Women's Health Study. Stroke 2003;34:565-567.

28 Amarenco P, Bogousslavsky J, Caplan LR, Donnan GA, Hennerici MG: Classification of stroke subtypes. Cerebrovasc Dis 2009;27: 493-501.
29 Newman AB, Shemanski L, Manolio TA, et al: Ankle-arm index as a predictor of cardiovascular disease and mortality in the Cardiovascular Health Study. Arterioscler Thromb Vasc Biol 1999;19:538-545.

30 Abbott R, Rodriguez B, Petrovitch $\mathrm{H}$, et al: Ankle-brachial blood pressure in elderly men and the risk of stroke: the Honolulu Heart Program. J Clin Epidemiol 2001;54: 973-978.

31 Tsai AW, Folsom AR, Rosamond WD, Jones DW: Ankle-brachial index and 7-year ischemic stroke incidence: the ARIC Study. Stroke 2001;32:1721-1724.

32 O'Hare AM, Katz R, Shlipak MG, Cushman M, Newman AB: Mortality and cardiovascular risk across the ankle-arm index spectrum: results from the Cardiovascular Health Study. Circulation 2006;113:388-393.

33 Resnick HE, Lindsay RS, McDermott MM, et al: Relationship of high and low ankle brachial index to all-cause and cardiovascular disease mortality: the Strong Heart Study. Circulation 2004; 109:733-739.

34 Hollander M, Hak AE, Koudstaal PJ, et al: Comparison between measures of atherosclerosis and risk of stroke: the Rotterdam Study. Stroke 2003;34:2367-2372.

35 Kernan WN, Viscoli CM, Brass LM, et al: The stroke prognosis instrument II (SPI-II): a clinical prediction instrument for patients with transient ischemia and nondisabling ischemic stroke. Stroke 2000;31:456-462.

36 Diener HC: Modified-release dipyridamole combined with aspirin for secondary stroke prevention. Aging Health 2005;1:19-26.

37 Hooi JD, Kester ADM, Stoffers HEJH, Overdijk MM, van Ree JW, Knottnerus JA: Incidence of and risk factors for asymptomatic peripheral arterial occlusive disease: a longitudinal study. Am J Epidemiol 2001;153: 666-672. 